\title{
Catching them young: The need for education- research connect in astronomically developing countries
}

\author{
Rajesh Kochhar ${ }^{1}$ \\ Indian Institute of science Education and Research \\ Sector 26, Chandigarh 160019, India \\ E-mail: rkochhar2000@yahoo.com
}

\begin{abstract}
We argue that the large-scale moronification of society brought about by the development of black-box technologies has resulted in lesser respect for and interest in basic science. Within science, there is a marked shift away from physical sciences towards life sciences.. In India and similarly placed countries the state's efforts to prop up astronomical research as a stand-alone, decoupled from college and university level teaching, is bound to be counter-productive. We also speculate on whether the recent economic melt-down and the expected trend towards some sort of economic nationalism would be good for astronomy and science in general.
\end{abstract}

Accelerating the Rate of Astronomical Discovery - sps5

Rio de Janeiro, Brazil

August 11-14 2009

\footnotetext{
$1 \quad$ Speaker
} 
It is a well established historical fact that for any discovery to take place, or make an impact on subsequent developments, it must be located in a culture of sustained activity. For creative peaks to rise, extant knowledge, especially the recent developments, must be well absorbed. Astronomy like all basic science today is a child of high technology. And yet unlike other disciplines where a new sophisticated facility tends to render the older ones redundant, there is place for all, big and small, under the astronomical sky.

In India and other similarly placed countries there is a sharp disconnect between education and research which is detrimental to both. Excitement of astronomy as an intellectual discipline and the value of the universe as a scientific test house must be conveyed to students when they are young so that in their youthful innocence and enthusiasm they may choose astronomy as a career or otherwise become supportive of it. It is thus important for senior researchers to be teachers as well.

\section{Black-box technologies versus basic science}

There are global trends and fashions that constrain the educational and research space currently available to astronomy. We must carefully analyze these constraints, and see what can be achieved within the given boundary conditions. We must also see whether the current global economic and financial crises can turn out to be beneficial for basic sciences. Even though globalization has been made possible by significant developments in technology, paradoxically enough, respect for basic principles of science has declined the world over. May be this is because the word wonder has disappeared from the dictionary of scientists and laypersons alike.

Fewer and fewer people are using their intellect the more and more so that rest of the humankind does not have to use its brains at all. This large-scale moronification of society brought about by the development of black-box technologies is of great cultural significance. There is so much of money to be made from intellectually unchallenging jobs that nobody seems to be interested in intellectual stimulation any more. Globalization has changed the employment patterns every where. This in turn has impacted the educational scene. Here I focus on those aspects from India which I believe may be relevant in a larger context also. In India higher education is still largely funded by parents. Their wishes and aspirations, peer pressure, and market demands determine the decisions of young men and women. Acquisition of employable skills rather than education in the classical sense seems to be the new mantra.

\section{Recent trends}

Some trends are clearly visible. (1) There is a decided shift away from science. Brighter students are opting for areas like commerce, economics, business administration, mass communication, entertainment industry, etc.

(2) Within science, there is a shift away from physical sciences towards life sciences. Since medical education is very expensive, many students opt for basic biology, which has come a long way since the 1930s when Lord Rutherford equated all non-physics science to stamp collecting! 
Availability of doctoral fellowships and post-doc positions in US has always been a consideration with young Indian scientists. If NASA was the magnet earlier, it is NIH now. (Note that just as in the 19th century, Royal meant England, national now means US.)

(3) Physical sciences, especially physics and mathematics, rank very low in students' priority lists these days. By and large they prefer a third-rate engineering degree to a good physics degree. Even when they opt for physics, it is with a view to doing MBA later or joining government administrative service.

Number of Ph. D. fellowships available in the country has not decreased. The number of first divisions and gold medals handed out by the universities has not changed. But the quality of students choosing a research career has by and large come down heavily.

\section{Laboratories at the cost of universities}

During the second world war, western governments commandeered the trained manpower of the universities and put it to use in the war effort. But, as soon as the war needs (not the war itself) were over, universities were revitalized. Unfortunately what was a contingency plan for the west was made into national policy by India which became independent in 1947.

Indian universities had been going very well in the first half of the 20th century. They were robbed of talent to set up national labs. At the same time school and higher education was expanded without any care for quality. There was a time when a school teacher's job was considered fairly attractive. Now it is the last resort. Given the level of facilities in schools, quality of books and caliber of teaching, it should come as no surprise that for majority of students' school years are time and talent lost.

I have heard experts, including Nobel laureates, complain about quality of science teaching in US, Switzerland, and Germany. One can well imagine the situation in countries down the line. As Anna Freud pointed out, "Creative minds are known to survive any kind of bad training". But the purpose of education system should not be to create an obstacle race where only a handful of entrants survive. Rather, it should help people transcend their limitations.

As already noted, very few students are opting for physics/ mathematics degrees. (Astronomy/ astrophysics are in general not part of university education.) To top it, lab/ library facilities are inadequate and teaching largely uninspired. Out of a total of about 400 universities in India today, it is only a handful that are active in research. Research institutes, all owned or funded by the central government, are well endowed. But they come into the picture when the students have obtained their master's degree. By the time the students are already fatigued. 
The country may not see it as such, but the unstated national policy towards research is tokenism: to make an impact on the world at large. It is like contriving the tip of the iceberg with the rest of it altogether missing rather than being merely invisible.

\section{Research as a corollary of education}

Science research should be seen as a corollary of science education. As a stand-alone, research is not sustainable. In the present system, the expertise of eminent researchers is of no use to those who need it the most, namely students working towards their first degree. The researchers are worried about improving their own CV by publishing in good journals, collecting citations, guiding Ph.D. students, etc. They rarely teach (except at Ph.D. level) or write textbooks. Also, providing students' lab and library require funds. Maintenance and upgradation of a lab require a certain level of infrastructural and industrial support which must come from outside the education system.

Indians take great pride in the fact that Chandrasekhar taught Yang and Lee who went on to win physics Noble prize. A recent factoid of pride is that the Google founders were mentored by an Indian professor. It would not cross India's mind that such mentoring should take place in India as well. India has started a handful of science universities (like the one I am based in) to provide rigorous science education for the students and to combine research with education for the faculty. This is a good beginning. Whether the experiment is successful or not only time can tell.

We have seen that globalization has adversely impacted the science education scene. Conversely, will the current meltdown benefit science? It is too early to say any thing. For one, the projected duration of the meltdown is being played down so that most people believe that the setback is only temporary. Personally I am inclined to believe that shrinkage of jobs in the west and onset of some sort of economic nationalism will help lesser countries retain their bright manpower and make use of it for their own good. Whether this manpower will opts for astronomy remains to be seen.

If I am forced to make a choice, I will place education above research. Well-taught, motivated students will automatically take to research. But the channel of research without educational feel will dry up. Astronomy is progressing very fast, incorporating into itself more and more disciplines. Pre-Ph. D. education must also correspondingly progress so that the gap remains manageable.

I would close by drawing your attention to an instructive observation recorded by a birdwatcher. Baby bird and mother bird are in the nest. Father bird brings in food and deposits it on the nest floor. Mother bird picks it up and feeds the baby. Suddenly the mother dies. Father continues to bring in food, but the baby dies of starvation, because the link has been broken. 
Father bird is the state funding. Baby bird is research. Mother bird is education. Without her the baby will starve no matter how well intentioned the Father bird is.

\section{References}

S. Arunachalam, Is science in India on decline?, Current Science (2002), 83:107-108.

P. N. Srivastava, (1994), Science in India: Excellence and opportunities, The Shaping of Indian Science, Vol.3:1982-2003 (Hyderabad: Universities Press), pp 1792-1821

K. C. Garg and B.M. Gupta, (2003), Decline in science education in India-A case study at +2 and undergraduate level, Current Science, 84:1198-1201.

Rajesh Kochhar, (2004), Shanti Swarup Bhatnagar: Life and times (Review essay), Life \& Work of Sir S.S. Bhatnagar (by Norah Richards). (New edition, Delhi: NISTADS) (First published 1948)

Rajesh Kochhar, (2009), Globalization, Mandalization and the Indian middle class, Culture, Society and Development in India (Eds: M .K. Sanyal and A. Ghosh) (Hyderabad: Orient BlackSwan). 